\title{
Drone Culture: perspectives on autonomy and anonymity
}

\author{
Garfield Benjamin \\ Solent University \\ garfield.benjamin@solent.ac.uk
}

[Author's Accepted Manuscript]

[AI \& Society]

\section{Abstract}

This article addresses the problematic perspectives of drone culture. In critiquing focus on the drone's apparent 'autonomy', it argues that such devices function as part of a socio-technical network. They are relational parts of humanmachine interaction that, in our changing geopolitical realities, have a powerful influence on politics, reputation and warfare. Drawing on Žižek's conception of parallax, the article stresses the importance of culture and perception in forming the role of the drone in widening power asymmetries. It examines how perceptions of autonomy are evoked by drones, to claim that this misperception is a smokescreen that obscures the relational socio-technical realities of the drone. The article therefore argues that a more critical culture of the drone emerges by shifting the focus and perception from autonomy to anonymity. This allows us to engage more fully with the distributed agency and decision-making that define how drones are developed and deployed. Rather than focusing on the drone as a singular, fetishised, technical object, a relational approach to the drone assemblage is proposed that highlights the competing human interests that define and resist drones in global politics and culture.

Keywords : drone, UAV, culture, parallax, simulation, assemblage, relational, socio-technical

\section{Introduction}

Drones have a problematic relation to existing human social and political structures. They exist high above everyday human reality in a space of vectors and virtuality. They are at once singular and multiple, controlled and autonomous, tool and agent, identifiable and anonymous. Their shifting and elusive nature is part of what makes them powerful and terrifying; it is this apparent indeterminacy that defines how drones fit into contemporary politics and culture. Perhaps the most prominent issue currently raging across industry, academia and government is the issue of autonomy, with calls for regulation or banning (Future of Life Institute 2015) not only of autonomous drones but also related autonomous algorithmic decision-making in machine learning systems such as facial recognition (Stark 2019). But in the gaps between the tensions, dichotomies and debates surrounding drones and AI, between the technical, legal, political, economic and military systems that constitute these machinic agents, lie the broader implications and impact of how drones are understood in social contexts: in short, drone culture. Culture is the medium through which technological, social and political norms are created, enacted and perpetuated to condition expectations and reactions. The place of drones in society evolves as part of how drones are situated in broader technocultures, a complex and fraught array of interests and representations that define the narratives used to justify or resist drones. Critical analysis and interventions in drone culture offer a way of challenging asymmetric influences over these narratives and norms that define the drone as the singular symbol of what is in fact a vast socio-technical assemblage. 
In their introduction to a special issue of Culture Machine on the topic, Coley and Lockwood asked "What then of drone culture? What of the fundamental weirdness of the drone that can be felt beyond its military operations and that refuses reduction to a set of standardized discourses?" $(2015,2)$. The issue collected different perspectives on the impact of drones on specific media and specific cultures. While it has been argued that the drone is a "cultural puzzle" in that "there is no monolithic drone culture, since the drone, as a device, is constantly reinvented" (Yehya 2015, 1;2) and it is certainly crucial to constantly emphasise the diverse natures, contexts and transformations of 'the drone' - a focus on perspective provides a functional locus for discussion that provides a depiction of the construction of drone culture as a mediator of the power relations with which drones are entangled.

There are many definitions and interpretations of what a 'drone' is, in contexts including toy, delivery platform, surveillance system or weapon of war. This is further complicated by its fuzzy borders with robots and its cultural conflation with machine learning and/or artificial intelligence. This article will focus on the ways that drones reconfigure global perceptual realities and cultures. It therefore expands on Jablonowski's discussion of the cultural image of drones, and the call to "decentre drones as objects of technoscience" (2015, 7). This provides a useful framing for assessing the broader cultural impact of drones as embedded assemblages. This article will take a relational approach to drones as a means of critiquing their status as a cultural construct, a relational assemblage of power relations that highlights the need to re-question the nature and role of humanity and society in a drone age.

Power relations here refers to asymmetries of influence over how drones are understood and operationalised, as well as the intersections of their differing impacts and the inequalities they engender. Power is taken as excessive, never "pure", and embedded in social structures to such an extent that even the decentralisation of traditional singular power (such as those models of power espoused by Western democracies) create even more oppressive sociotechnical means of control (Žižek 2007, 307). In the specific case of the drone, this power is also necropolitical (Mbembe 2003), an asymmetric power over life and death that converts its potential victims into a "walking dead".

The discussion will build on the parallax philosophy of Slavoj Žižek, in conjunction with the work of Gilles Deleuze and Jean Baudrillard, to analyse cultural representations of and transformations by the drone as, at once, a simulated gaze, a symbolic assemblage, and a line of flight across stratified territories. This will lead towards an assessment of the many critical perspectives that decentre drone culture as a component of broader cultural tensions and divisions, to ask what power relations are concealed within the anonymity and perceived autonomy of drones.

\section{Parallax culture and the autonomy-anonymity divide}

The displacement of perspective is a key characteristic of the drone, in relation to both its operator and its potential viewers (including victims). The drone is an object that is perceived (as autonomous, as symbol, as threat), that alters the space in which it is perceived, and that is also a means of altering perception. Understanding the complex relational nature of drones requires an assessment of perspective. This article will take as its starting point Žižek's notion of parallax - an epistemological shift in the subject that creates an ontological shift in (social) reality (Žižek 2007, 7). This framing builds on previous work applying parallax to cultural split between physical and digital media, and the possibility of viewing both sides simultaneously as contributing to a cybernetic act of resistance (Benjamin 2016). Parallax is also fundamental to thinking about socio-technical assemblages and the way technologies "comprise both artefacts and associated practices" (Suchman, 186). Here, this emerges as an ideological split between the drone as an object or symbol and as a set of socio-technical relations.

While the optical component of parallax and shifting relative perspectives is important when considering the drone, this concept goes further into the creation of 
social reality by changing perspectives and the power relations this entails. Perspective counts - whether between first and third person visual formats, between Western and non-Western cultures and politics, between attacker and victim(s), between the individual operator and the chain of command, between anonymity and autonomy. There is a politics and a culture of parallax in creating and maintaining these distinctions. The manipulation of perspective by mediatised representations and their proliferation through wider culture entrenches certain viewpoints as dominant within global power structures. Who defines drone culture defines how the drone is constructed and operationalised in global socio-technical relations.

The drone embodies these parallax functions of a change in perspective that instantiates changes in the objects perceived, both of the drone itself and of the world through the drone. The dominance of one perspective, one culture of the drone, leads to an erasure of alternative perspectives. Taking a critical parallax approach promotes viewing multiple perspectives at once, to expose asymmetric power relations and foregrounding previously marginalised groups. This is not a synthesis or resolution; there is no finding of common ground (Žižek 2007, 4). Instead it is a simultaneous viewing of conflicting perspectives. Parallax has been used as a method of viewing different cultural versions of the same landscape, particularly to emphasise designations of territory that shape space differently between colonising and indigenous populations (Timms 2008). Parallax is also thought of as "voices in conversation", acknowledging "shifting subjectivities and situatedness which directly influence the constructs of perception" (Sameshima 2007, 293-4). Across these uses of parallax is a critical political process of rethinking how culture shapes reality. Here, then, parallax culture involves viewing different aspects of the socio-technical assemblage of the drone.

The focus of this article is the cultural parallax of drones along the perception of autonomy and anonymity. The dominant narratives of drones and other manifestations or representations of $\mathrm{AI}$ in vehicles, robotics, healthcare and algorithmic decision-making - are focused on debates surrounding autonomy (for example, Sharkey
2019; Ficuciello et al. 2019; Cunneen et al. 2020). Are drones able to or allowed to make decisions over life or death without human intervention? This is certainly a necropolitical question. Yet this autonomy is largely a matter of perception. Autonomous drones - in the sense often depicted in dystopian science fiction - simply do not exist. Rather, autonomy in drones speaks to a broader trend not towards machines making decisions without humans, but towards humans offloading responsibility to the perceived (and erroneous) notion of machine learning systems as objective. The drone therefore acts as a placeholder for this deferral of accountability using systems that tend to exacerbate existing biases and inequalities.

We argue throughout this article that the appearance of the drone as autonomous is an effect of cultural parallax over the use of the drone for anonymity. In a behavioural context, anonymity is "not being unnamed but being unknown" (Burkell 2006, 189), and in tech ethics this separation from naming allows us to consider anonymity as the "noncoordinatability of traits in a given respect." (Wallace 1999, 21). The controlling interests of a drone may well be named - often a specific military - but the specific individuals deciding how they are operated are largely unknown. Anonymity is also social - it requires "an audience of at least one person" (Marx 1999, 100) leading towards a parallax and relational understanding of the power of drone anonymity to, for example, its victims. Viewing the drone not as an entity but as a network of power relations, anonymity is usefully understood as unlinkability - "the state of being not identifiable within a set of subjects" (Pfitzmann and Köhntopp 2001, 2) - the blurring of complex entities and relations that forms the drone as a socio-technical assemblage. Anonymity in a privacy setting can be understood as allowing one "to act, transact, and participate without accountability, without others 'getting at' them, tracking them down, or even punishing them" (Nissenbaum 1999, 142). In this sense, anonymity is about being "unreachable", which is certainly true of those shadowy forces designing, building, selling, buying and operating drones. The drone acts as a cultural stand-in that obscures power relations and shifts perception onto the singular technological artefact and away from the various agents that define it. The drone is 
a medium for this technocultural mediation of contemporary power. By adopting a parallax approach to bring different perspectives on the drone into antagonistic discussion, we can offer a useful critique of the relational socio-technical assemblage that constitutes the drone.

\section{The simulated reality of drone warfare}

Roger Stahl states that "the drone is not simply a weapon, but also an emerging medium for representing conflict" $(2013,659)$ that incorporates, manifests and codifies the representation of its own actions resulting in a "cultural optics" of the drone. Indeed, it is the perspective of the drone that occupies the viewpoint from which not just drone warfare but much of contemporary warfare is mediated to the public through the press and popular culture such as games or films. This extends from the bomb bay view of the Enola Gay through guided cruise missiles in the first Gulf War on to drone operations across the globe. The operationalised overhead view, targets picked out in crosshairs, has now become our default perspective for news reports, reconfiguring the way in which our culture accesses information. The politics of this aesthetic also places an excessive emphasis on the view of the drone controllers, often the ruling elites of Western wealthy nations. This echoes the prevalence of satellite imagery in, for example, Google Earth and its alteration of our perspective on the planet.

The drone view in particular enacts several displacement of perspective: the shift from first to third person (command or god's eye) view; the perpetual anonymity of the drone itself as the point of perspective; and the extreme telepresence that physically detaches pilots from a warzone, converting what has always been depicted as a visceral horror (or glory) in culture into a gamelike perspective on screen. As one drone pilot has been recorded as saying, "it's like a video game. It can get a little bloodthirsty. But it's fucking cool" (in Singer 2009, 332). This valorisation of the mediating process of detachment trivialises the material reality of the drone in a digital cultural context. As Science for the People magazine predicted in the 1970s, we are headed for "Total Remote War" in which "as never before, the societal and cultural heritage of an Empire will be turned into a genocide machine." [...] "The separation of illusion and reality vanishes for the television warriors" (The Editorial Collective 1973, 37). This is the embodiment and ultimate end of technoculture, encompassing videogames, surveillance, post-9/11 fear, neoliberal politics and Silicon Valley rhetoric.

The drone is therefore a symbol of the simulation of warfare, in the full sense that Baudrillard describes. This form of simulation first "masks the absence of a profound reality" before pushing to the point at which it "has no relation to any reality whatsoever" (Baudrillard 1994, 6). And yet the deployment of drones has very real consequences for their victims, who only see the anonymous technological weapon before the horrors begin. The myth of perceived autonomy, of the perceived detachment of drone warfare, requires a counter found in what Žižek describes as the importance of the "reality of the virtual" over "virtual reality" (2012, 3 ). This is a shift away from the mediating lens of virtual reality - a fundamentally null concept of pure simulation that removes real power structures from view - towards bringing into view the real effects of simulation.

Patrick Crogan (2017) discusses the military origins of videogames, and Spacewars! as an early game based on drone-like space warfare controlled from a top-down "commander" perspective. Technical and cultural aspects of videogames developed simultaneously as the simulation of warfare that would lead towards drones. The shift from traditional material industry towards digital labour, simulation and abstraction in this highly mediated approach to killing emerges as the fulfilment of the "military-entertainment complex" (Lenoir 2000). Chamayou describes drones as the "anti-kamikaze", a machinic response to suicide bombers that can continue operating "as if nothing happened" $(2015,84)$ : a complete removal of risk. Crogan describes the transition to drone warfare as "the projection over the inhabited world of a simulational model of the contested space" in which " the inhabitants of the spaces of concern in the global war on terror are better understood 
as environmental elements or threats", part of "a permanent realtime of preemptive, pan-spectrum surveillance" (2016, 641). Crogan emphasises drone as (the visible) part of a complex coordinated computerised/automated system. In this system, the "drone encounter" emerges from spycraft and surveillance more so than it does the tradition of warriors or pilots (Piotrowska 2017, 40).

Drones are elusive; they exist simultaneously everywhere and nowhere. The eye in the sky, god-like perspective of drones enacts a gaze tied to prescience and control, to "surveillance and annihilation" (Chamayou 2015, 37). This shift in perspective, which creates a shift in the reality of this new type of warfare, converts the combat space into a "game of drones" (Andersen 2014). The dangers of drone warfare "do not solely emerge from the destructive capacity of that technology: they arise from the increasingly tenuous position of the contemporary U.S. soldier" (Andersen 2014, 361). The problem, it seems (at least in those countries controlling the drones), is the increase in a perceived weakness from "demoting the soldier hero" (Andersen 2014, 364) through the shift into war only as a simulation, a game, an abstraction, detached from the reality of the war itself. It is no longer the lone human hero (the "player character" of videogame culture) who has the power, but the broader technical military systems. This game structure, in which the system creates clear territories and rule-based options, echoes real world cultural issues around whether drone pilots are 'real' pilots with the removal of risk. This shift in the perceived nature of military power and personnel is an important component of drone autonomy. Against the perceived necessity of having a human "in the decisionmaking loop", is the question over individual human moral agency, the psychological effects on drone operators, the automation of everyday life more broadly, and the autonomy of states, military and industry as holding the global "command view" of society.

The "abstracted gaze" of the drone aesthetic is a simultaneous flattening and sharpening (Lichty 2013), and it can also be used critically to sharpen social realities and the real shifts that are created by the altered perspectives of global drone warfare. The broader videogame and surveillance cultures that enable and exacerbate drone culture can be seen the expansion of drones back into these fields. Whether for military, entertainment or sport, drones are themselves simulated in digital games for training purposes. The cultural discourse and mediation here circles round on itself by removing even the material risk to the drone as object.

The further step of perceived frictionlessness highlights the risk-free god-like privilege that drones occupy (not counting the reduced but still significant psychological impact on drone pilots and the continued risk of PTSD (Chappelle et al. 2014).

Noys, in his critique of drone metaphysics, describes how "drones inhabit a field of theological metaphysics, embodying dreams of transcendence and destruction that have haunted the Western imagination" $(2015,2)$. There is no real metaphysics of the drone, only the set of relations that constitute them as assemblage. Like the artificial intelligence myth (also known as marketing hype), the perceived autonomy and anonymity of drones is linked culturally to a higher power, embodied literally with drones from their top-down perspective. Even the names of military drones evoke theological language: US Air Force and UK Royal Air Force designated 'Reaper' drones carry 'Hellfire' missiles to bring down righteous wrath on the enemies of the state. This approaches Thacker's "dark media" (2014), the mediation between two realities that "theologizes media theory" (Coley and Lockwood 2015, 9). This cultural image fits into broader theistic narratives of $\mathrm{AI}$ in which perceptions of autonomy ascribe agency and therefore power to technical systems (Singler 2020), apt for the mysticisation of drone culture in the 'godlike' perspective able to see all, know all and destroy all while remaining invulnerable.

The theological component remains mobilised in the recent UK shift in designation to Protector - now evoking a more comforting image of holy violence to the public at home in order to justify drone use. This has been particularly highlighted in the UK military's manipulation of visibility and regulation in order to bypass protest and acclimatise the public on the path to allowing drone flights over home territory (Harris and Evans 2020). Not only do drones occupy a physically 
superior perspective, but they act as a tool for their operators and commanders (as well as the politicians who approve sanction their use) to attempt to take on a mythic status of godlike superhero. For the operator, military apparatus and political power, the drone operationalises the simulation of space as the space in which their power has meaning, an expression of their new virtual domain detached from physical presence. But for their victims, the drone is a symbol of anonymous Death, a dark power that is ever present, watching, waiting to strike mercilessly and without warning.

The corporate naming of these models of drone as 'Predator' highlights the other perspective of power that controls their development and pushes their deployment. Evoking the business 'shark' eternally hunting for profit, the drone industry forms another region of the assemblage that pushes for more and more drones to be operationalised by selling the appearance of power and risk management to governments. General Atomics, the company behind Predator drones in use by US, UK and Indian military, amongst others, are exemplary of this system. The company itself is a sprawling mass of affiliated organisations, centred around their aviation arm but spanning other areas such as energy and research/education. They position themselves as a "defense and diversified technologies company" (General Atomics 2020), highlighting the distributed assemblage of actors involved in creating drone technologies. The products they sell are equally diverse, including not only the hardware and software that forms the specific individual drone but the linked array of control, communication, sensing and processing apparatus, as well as training services, that are all brought together to make the drone assemblage function. Their marketing shows a clear focus on the desires of military procurement and how that in turn is used to persuade politicians: the GA-ASI Twitter feed is filled with language of "seamless joint battlefield integration" (@GenAtomics-ASI 2020a), breadth of missions operating in the \#grayzone (@GenAtomics-ASI 2020b), and the priorities of distance and protection of assets. The company creates an image of a complex sociotechnical assemblage as the appearance of smooth, clean power across the globe while minimising risk, embodying the desires of tech companies and military for control through simulation. The sprawling chaos of natural and human landscapes are abstracted into stock images of the world crossed by blue lines representing metrics, vectors and bottom lines: dehumanisation in the symbol of the drone.

This corporate imaginary is perhaps why the drone has taken on a popular role among CEOs of other large tech companies that contributes to the conditioning of broader culture through corporate desire and slick marketing, from Amazon's attempts to roll out mass drone delivery to Facebook's plans to use drones to dominate internet access in remote areas without existing infrastructure. This furthers the attempts by the tech industry to disappear into unaccountability as they become the sociotechnical structures and cultural mediators that plague digitalised society more widely such as the non-neutral function of the algorithmic control over information (Noble 2018). 'Unmanned' represents anonymity, not autonomy. 'Remote Piloted' is therefore perhaps a more appropriate term to use to emphasise the human network behind the drone. The cultural and political debates surrounding drones act as yet another embodiment of the problematic definition of 'human'. The Stop Killer Robots initiative, while offering valid and important arguments on the handover of lethal decision-making to autonomous drones, fails to fully take into account the underlying broader sociotechnical systems of power asymmetry between humans. For example, even if drones are given autonomous decision-making capabilities, the choice of where, when, how and under what terms such systems are designed and deployed will remain a very human military and political decision. Placing the autonomous killer drone as the antagonist to humanity displays the sheltered perspective of the currently dominant global culture (largely white, wealthy, Western, male).

Establishing this dichotomy - humans vs drones downplays the construction of existing drones as an assemblage of simulation and anonymisation, in a way that risks denying the place of their victims within the group designated 'humanity'. This framing of the debate, only the latest in the long history of mobilisations of the term 'human' as an exclusionary 
tactic, displaces human political realities with the techno-fetishised fictions of drone culture. Piotrowska $(2017,35)$ warns that even critical drone culture can risk removing agency from victims even as it foregrounds the deaths of innocents and questions over the ethics of drone warfare. This argument engages in what can be described as necropolitical debates over which traumas matter more or less, whose 'humanity' matters more, and which victim is more or less 'human'. There is a comparative absence of drones from drone culture, their disappearance into mediator in defining the perspective from which we view drone flight or action. The visual culture of the drone thereby furthers asymmetric representations by prioritising the perspective of the drone, and thereby of military-entertainment desires rather than the narrative perspectives of the victims on all sides of the assemblage, who become only and forever 'victims', 'collateral damage', objects of war. Any technical system is always-already an assemblage of parts, programs, networks, data, and of coders, designers, operators, users, victims. It is important to constantly critique and address the power imbalances that establish the terms of such assemblages.

The drone also provides the god-like perspective such powers are attempting to embody, not only as they threaten others but as they perceive their own position. The over-quantification inherent to simulation rears its head here as a process of desiring-production in a machinic assemblage. Deleuze and Guattari (2004a) separate the technical machine as "merely an index of a general form of social production" (34) from the desiring machine as "a fundamental category of the economy of desire [...] both technical and social" (35), always connected to other machines and conditioning the dysfunctional flows of desire and therefore power. These framings of desire in relation to symbolic power provide a way of approaching the drive towards further simulation, further dronification of global interaction and socio-technical assemblages. There is an ideological gesture in treating a drone as autonomous, turning a complex set of interactions into a single visual symbol. Combined with the game-like enforcing of objectives that control the desire of, for example, the operators, the drone as a smooth singular expression becomes part of the operationalised landscape.
Here we see a perversion of Deleuze and Guattari's Body without Organs: the illusion of seamless, frictionless motion without parts. Noys explicitly addresses this problem, stating that:

The desire for a final deterritorialisation that can slip into a smooth space of resistance is not only unfaithful to Deleuze and Guattari's warning, ' $[n]$ ever believe a smooth space will suffice to save us', but also remains within the field of drone metaphysics. (Noys 2015, 17)

Again, the illusion of drones as metaphysical objects is an ideological move to manipulate their misrepresentation, and thereby acceptance, in broader culture. Against the mythic and all-powerful perception of drones in culture, Noys highlights the danger of techno-fetishism:

To treat drones as if they were the 'travelling eye of God' is to flatter this mundane and brutal surveillance and killing device. We may give a technological object, or technological assemblage, a philosophical dignity it does not deserve. (Noys 2015, 3)

This emphasises drones as complex systems with specific consequences. While they may have limited automated functions (similar to the autopilot familiar to aeroplanes), they are far from autonomous. There will be no AI takeover manifested in drones turning against humans, raining down fiery death from the heavens like vengeful machine gods. But Noys is not attempting to limit the potential dangers of drones, only to ensure the focus is properly directed. The use of drones carries with it many dangers, but this stems from their construction as a relational technology. Each drone is part of a global network formed not only of technical parts and operators but also social and political factors and agents. A drone can be considered "a political and historical assemblage, rather than a discrete device" (Bloomberg 2015, 1). It is the social and collective machinic assemblage that precedes and is presupposed by the technical element (Deleuze and Guattari 2004b, 439). Drones and drone strikes are often self-perpetuating feedback loops of fear 
as political relations, the connecting of simulated and real spaces in their broader historical contexts and geopolitical reality.

\section{Symbolic assemblages of technosocial relations}

It is the wider socio-political network of power and control that enables the drone to operate as the technical expression of power relations. The entire set of relations that support the development, deployment and justification of drones forms an evolving cultural narrative that entrenches existing socio-technical inequalities. Fig.1 shows the relations assemblage that constitutes a drone, specifically a military drone. This approach builds on Birhane and Cummins's outline for a relational ethics of AI. They emphasise "centering the disproportionally impacted" (Birhane and Cummins 2019, 2), as well as moving beyond prediction and solution towards understanding and the creation of social norms. Here this is extended and applied to the drone in seeking a relational understanding of the sociotechnical assemblage, acknowledging that it is always part of an ongoing political and cultural process. Figure 1 demonstrates this by placing the victims at the centre, with the varying levels of power and influence increasing towards the edges. The addition of a parallax approach encourages us to view the different perspectives and narratives that emerge across this assemblage.

We should emphasise a few key points about this diagram: (1) it is non-exhaustive - there will be many more further relations that spiral across and outside this diagram; (2) it is a global assemblage - even when the drone is operated by a single nation; (3) the technical components should not be considered agents - like interests and underpinning concepts, they are enabling functions or narratives; (4) each entity on the diagram is neither singular nor heterogenous - there are multiple iterations of any given role, and each person or group performing a given role has their own experience and perspective which we should seek to understand. This final point includes the broad array of direct and indirect victims. Pilot PTSD - often exacerbated by the detached simulation construction of the assemblage - can tear apart individuals and their families, while broader prejudices and cultural perceptions can lead to wider discrimination of communities seen to align with target organisations - particularly Muslim communities living within the countries where drones operate as well as within the 'home' countries operating drones.

The decision-making process spans not only the globe but also different scales of the assemblage. Ethical decisions occur at the individual, organisational, national/international, policy and cultural levels. We therefore need to think across scales of perspective to understand the relations. This includes also various degrees of displacement. For example, a drone operator might be in a different facility or even country from the operational commander, or facial recognition used to identify targets might be conducted at a separate technical facility in yet another part of the world. Similarly, the political and legal structures might span various countries and agreements. And the perceptions are always mediated through the culture of the drone, its aesthetic and social structures that can form barriers of understanding between decision-makers, victims and wider publics.

Across these areas and perspectives in practice, the overarching narrative of drone culture often persists in operationalising the costs of the drone assemblage as percentages and risk assessments, popularity points dropping in the polls, and legal bureaucracy. It remains detached into the simulated space of abstract warfare. The relational diagram highlights the expansive human element in drone deployment, emphasising the displaced and relational responsibility in play. This demonstrates the lack of autonomy in drones, and the distributed decision-making by individual and national human agents, the perception of drones in relation to autonomy and AI persists in culture.

Such assemblages are relational, and should be critiqued in relational terms, but we also acknowledge the asymmetric power structures of the sociotechnical assemblage of the drone. The drone itself - as object, as appearance and as symbol - forms an affective barrier 
within the relationality that dehumanises the assemblage. On one side, the victim is dehumanised in their subjectification by the total surveillance weapon system. On the other, the complex moral, legal and military decision-making processes are subsumed in the terror of the appearance of the drone, similarly dehumanised in their assemblage of drone-as-weapon.
Bringing to light the chains of command and responsibility is important, from the pilot up through military structures as well as sideways into the political and technical basis of the network and machine, as is moving away from the perspective of instrumentalising cultures that reduce drone-victim interactions to those of target and collateral as mere data.

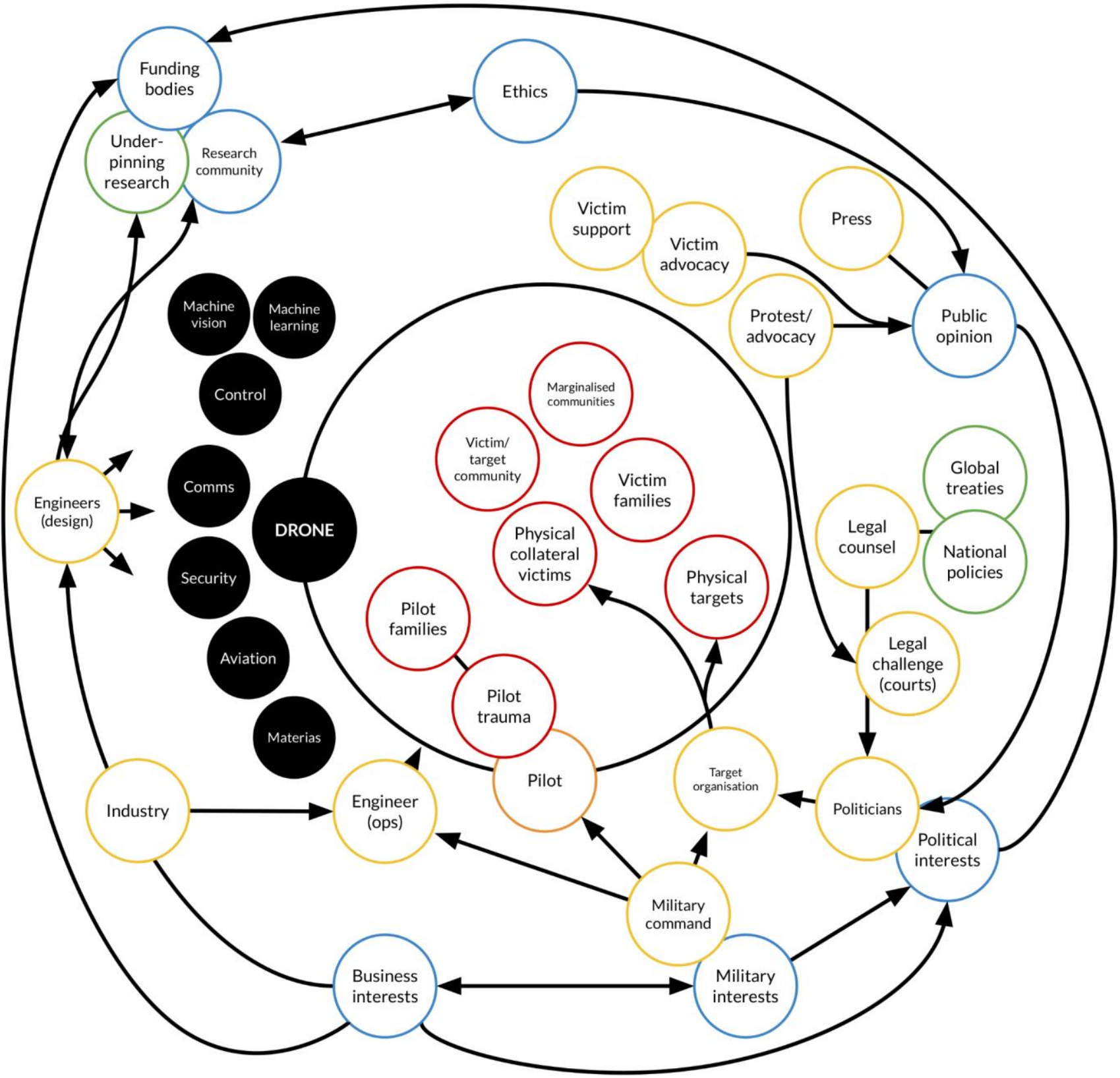

Fig.1 The drone as relational socio-technical assemblage 
The debate is muddied by the persistence of autonomy as a primary perceived threat. Prominent examples of this include the Campaign to Stop Killer Robots (Campaign to Stop Killer Robots 2018) and the Open Letter on Autonomous Weapons (Future of Life Institute 2015), both of which draw members and signatories from key figures across the globe in industry, academia and politics. Many of those joining the campaign (such as Noel Sharkey) emphasise that the issue with giving drones autonomous killing power is that they are not capable of such autonomy. This line of critique shows the relational nature of drones as embodiments of connected and distributed technical and political systems. However, the broader rhetoric and perception of the campaign leans back on the mythic metaphysics of drones that conflates definitions of autonomy (exacerbated by the fear-mongering science fiction approach of signatories such as Elon Musk). While potentially protecting the likely victims, the campaign shows very white Western privileged fears - autonomy here is the threat, a machine unable to discern human morality or going awry through misinterpreting dynamic and chaotic situations.

Autonomous decision-making for drone military action is born of a state/corporate desire to extend its will inexorably through technology, removing the possibility of ethical questioning by intermediary human operators (though this illusion of course ignores the many major issues with truly autonomous drones). But decisional autonomy is not the prime threat for victims (particularly innocent collateral victims) with systems in existence today; for children in Pakistan or Afghanistan a drone is terrifying enough already, both for the direct threat and precisely because it is a symbolic representation of an anonymous power situated thousands of miles away. Autonomy here is a power relation between humans and a prioritisation of perspectives in drone culture. It is a restriction on agency. The appearance of the drone to its victims as an airborne threat is marginalised by the dominant perspective in which the drone as object appears as a hard limit on its victims' autonomy, reducing them to numbers on a risk assessment readout.

Adopting a relational parallax approach to thinking about drones highlights the perception by victims or publics on the ground while acknowledging the shifting and self-perpetuating socio-technical assemblage that mobilises the fundamentally empty concept of the autonomous drone as a means of legitimising and exerting symbolic global power. Thus we can think of the drone simultaneously as an elusive appearance, symbol and simulation of power in abstract global technopolitics, and as the marginalised narratives in which it is a very real and material threat. This further asserts the usefulness of parallax as the shift in perceived power in turn shifts the balance of the entire assemblage of the drone, and indeed the assemblage of drones and drone warfare as a political force. By the act of unleashing a drone, its controlling entities are making a collective global statement of power that justifies its status, and with each strike we see its meaning as a symbol of power further guaranteed by its evolving cultural perception.

Lacan's conception of the gaze is important here, and the gap between the space in which the subject sees itself and the space from which the subject sees itself (1977, 144). This operates on either side of the power asymmetry of the drone assemblage. From the perspective of the victim, it converts their lived experience into the simulated zones of conflict in which they now exist, from their conventional social relations into broader geopolitical territories. It also constructs a specific point from which they now see themselves as object; (how) is the drone looking at me? Am I being seen as a target?

\section{$5 \quad$ Lines of flight(paths) across simulated territories}

One of the key debates around drones is "the diffusion of the conventional battlefield and the muddying of 'territory" (Coley and Lockwood 2015, 2). The abstraction of arbitrary gamelike divisions of smooth information space obscure the different contexts and specific territories, perspectives and cultures upon which the drone assemblage intrudes. But while drones alter our perception of conventional divisions of territory, acting as vectors of political force across 
physical spaces, their simulation of virtual battlefield spaces generates new processes of designating territories. Bloomberg (2015) highlights how drones organise territory, social life and our perception of the future. Not only do drone images redefine our relation to and conception/perception of the Earth (whether in battle, war journalism or nature documentaries), but their processes of simulation have a territorialising effect on conflict zones, delineating spaces not according to geographic or social realities but according to shifting political targets.

This links closely to Deleuze and Guattari's (2004b) conception of territory and (state, capitalist) processes of territorialisation, connected via codification to the process of stratification (45). The link with the earth and its history, but also its recoding as territories of control in a process of "imprisoning intensities", recalls the drone as historical and political assemblage, for the drone constantly codes new simulated territories formed of killzones, designations of ally, neutral or enemy, and the flows of surveillance information that inform the global drone networks. The victims in such an assemblage therefore remain enclosed in their role, separated not only by physical distance but by cultural barriers defined by the power relations of the drone.

The assemblage rests between one such strata and the potential for flight. The assemblage is territorial, with lines of deterritorialisation that cut through it. These lines of flight offer critical and relational pathways that can open the assemblage up to other assemblages, and can open the territory onto "a land that is eccentric, immemorial or yet to come" (556). But against this move for deterritorialisation, state machines always seek to reterritorialise, by obstructing, segmenting or curtailing potential lines of flight (561). These lines of flight acknowledge movement as relative, and can be read as the process of decentring with which we can critically adjust the cultural perception of the drone.

The ultimate deterritorialisation for Deleuze and Guattari is the Earth as a whole, emphasising the full relationality of geopolitics that should be taken into account in order to fully apprehend drone culture(s) in their global and specific manifestations. This is a shift in scale, a shift in perspective that constantly rewrites the ontology of the drone, an ever moving set of boundaries that simulate and dissimulate, and against which Deleuze and Guattari seek a "collective assemblage of enunciation" (98) that deterritorialises and decentres the drone into something other. This is the task of realigning the socio-technical assemblage of the drone to foreground the perspectives, narratives and voices of victims as well as the dissenting voices of those on behalf of whom the drones are being used.

The same technology can be put to use as either a tool or a weapon (435-45). The tool moves in a relative speed of linear displacement: a set task with a scope of change limited to the preordained purpose of the territorialising and stratifying functioning of consciousness. This is synonymous with the simulation that perpetuates the functioning and perception of the machinic assemblage. By contrast, the weapon is always moving in an absolute speed, a manifestation of force in space and time as a free action with unlimited scope. This conception disrupts the idea of the drone as military weapon. For state power, even 'weapons' are tools. The drone is instead truly 'weaponised' when political resistance takes hold of the socio-technical assemblage of the drone to enact opposition as a parallax shift in perspective that recentres marginalised voices and alters the power balance of drone culture.

The drone assemblage operates a constant de- and reterritorialisation, cutting across conventional geographical and political divisions and replacing them with flight paths, vectors, the machinic gaze and new simulated territories. Lichty (2013) identifies in this "network of gaze" a problem of operationalisation, of transformation and "programmatic framing" that converts objects with social meaning (a house, a person) into an objective, a target. In some ways, the drone already includes its own processes of deterritorialisation, disrupting conventional state territories with a new expression of political power, while displacing the perception of this power from the networked assemblage onto the image of the drone as autonomous entity. Shaw and Akhter (2012) describe the drone as "a political actor with a fetishized existence, and this enables it to violate sovereign Pakistani 
territory" (1490). Power asymmetries emerge once more as one (or a few) states seek to deterritorialise conventional agreements and boundaries in order to occupy the role of global big Other as the guarantor of meaning (often expressed as a desire for peace or democracy, which can easily be read as dominance and total control).

Once again, we reject the appropriation of critical perspectives by the dominant military/tech culture surrounding the myth of the drone. For example, Žižek identifies a particular (superficial or perhaps mis-) reading of Deleuze by a hypothetical yuppie in which the philosophy comes to embody the frictionless dream of contemporary economics, marketing and social status, suggesting that Deleuze risks being hailed as the "ideologist of late capitalism" (Žižek 2012, 163). In the assemblage of the drone, we can see this risk spread further even into the realm of the state. The transformation of battle space into a smooth surface, the line of flight as a radical alternative to conventional warfare that destabalises traditional notions of territory, the nomadic appearance of the drone as the weaponisation of infinite movement, rhizomatic strikes anywhere and anytime: these rhetorics could easily be seen in a brochure for drone systems or a misreading of A Thousand Plateaus. The complex relational networks and power structures that attach themselves to the drone assemblage need to be constantly shifted and reemphasised to foreground marginalised perspectives. Humans are not just resistance to drones as a separate category of agent (in the manner of Stop Killer Robots or calls for the abstract and fetishised notion of 'humanity' in decision-making); the different human perspectives in play offer critiques of the full network of human-technical interaction.

The problem becomes one of decentring that which already decentres our perception of reality, of deterritorialising the machinic assemblage that itself deterritorialises conventional power relations. As Žižek suggests, "cyberspace phenomena render palpable in our everyday existence the deconstructionist 'decentred subject" $(2006,99)$, and this can be seen clearly in the simulation processes of the drone as a rendering 'cyber' of physical space. The task of a critical drone culture, then, is perhaps to shift our perspective away from the drone as object, to place the drone in parentheses in order to highlight the broader assemblage that defines its function and global impact. The fetishisation of autonomous drones as a core concern should not be normalised as a distraction from the manipulation of anonymity by the governments and corporations who use them. Even if autonomous drones are developed, there will always be the question of their design and deployment, a continued human decision-making process that escalates existing human power asymmetries. The decentring of the drone is the highlighting of its embeddedness in broader assemblages. Critical drone culture is therefore the altering of perspectives to allow alternative collective enunciations to be voiced and more equal sociotechnical assemblages to form.

\section{Conclusion}

From a starting point of issues of perspective, this article has established the drone as a technology of simulation, a socio-technical assemblage, a symbolic basis of global power and a shift in our conception of space and territory. It is outlined the dominant culture of the drone as emphasising perceived autonomy as a means of concealing either some or all of the broader assemblage, a power play that often diminishes our ability to fully perceive the effects of drone technologies and their deployment across the world. It has also suggested that critical drone culture emerges from the disappearance of the drone as a fetishised object, in order to decentre the power structures and bring alternative and collective perspectives into view. But if drone culture can aim towards removing the drone, what of the removal of the human from the assemblage? Amidst the technical and political forces at work, the role of the individual human, particularly both the operator and the victim, is often either one of absence or of the process of disappearance. While drone autonomy may be questionable today, we can ask what level of human decision-making really takes place in self-perpetuating power structures and cultures. Whether by malfunction, the absence of human interaction, or the domination of mediating cultural representations and asymmetric systems of power - will drones become autonomous by default? Packer and 
Reeves (2017) describe the drive towards automation in drone weapons and drone media as a process of "humanectomy". The decentring of humans from the drone assemblage is a strongly political gesture to deflect responsibility - the ideology of anonymity through the appearance of autonomy. The human team developing, designing and deploying a drone system is often subsumed into the symbolic appearance of the drone, and the extension of the human by the technical expression of the drone highlights a desire to become this frictionless, godlike technology.

Decentring the drone can prove difficult, as it pulls back towards the appearance of an autonomous agent we are seeking to emulate, the desiring-production of asymmetric socio-technical assemblages. The anonymising process of drone relations, and the cultural feishisation of the technical object risk the widespread simulation of drone relations by humans, a mass instrumentalisation under the will of nebulous and anonymous loci of power. Instead, we can focus on the power structures of the networked assemblage to find ways not only of decentring but destablising the symbolic structure of the drone and alter its perception as autonomous bearer of power. A critical operation against this power structure can emerge from highlighting the uneven removal of different groups of humans, and the reinsertion of marginalised groups more prominently within the assemblage. The PakistanUSA-France collective art project \#NotABugSplat placed giant images of Pakistani children (who were either victims of drones or had lost their families to drone attacks) in full view of the drones circling above. And yet the target audience was not the drone operators themselves, but the wider global community. The images were printed on useful fabric that would be taken up and used by locals, giving a sense of impermanence to the statement of collective existence. The real target was the global surveillance network that would capture and store the work (in, for example Google Earth's satellite images), rendering both the victims and the drone perspective visible to a wider audience. This is a reinsertion of human connection of and through the drone as a medium for potential collective action. The reappropriation of multiple views on the drone acts as an artistic process of parallax, seeing multiple perspectives and both sides of the power structure at the same time.

Drone culture can bring out relational approaches to our social, technical, political and historical global assemblages, critically disrupting the smokescreen of the perceived drone identity as autonomous agent and bringing to bear the embeddedness of human agency in drone decision-making. There is a need to constantly reemphasise the very human systems of power and decision-making that always underpin the design, development and deployment of these technologies. Critical drone culture can resist the fetishised perceptions of autonomy that further escalate the drone as a simulated agent, detracting from existing political assemblages and biases that allow its use as a tool for surveillance and destruction with impunity. Drones, operators, victims, commanders, engineers, researchers, politicians: all are important components in our geopolitical environment. Each has their own perspective on the drone and its implications. Understanding the cultural level of the drone that underpins the socio-technical assemblage and its interaction with society enables a parallax view across different perceptions, and allows us to recentre marginalised voices against power asymmetries. The drone should not be allowed to be mobilised as a media effect that obscures the complex and shifting relations at work. When it comes to culture, autonomy is not the problem with drones, anonymity is.

\section{References}

@GenAtomics_ASI (2020a) Seamless joint battlefield integration starts with MQ-9B - the strategic and tactical solution for the Indian Armed Forces. @adgpi @IndiaINF @IAF_MCC \#India. Twitter 16 March 2020. https://twitter.com/GenAtomics_ASI/status/12396 00325973233665.

@GenAtomics_ASI (2020b) An effective strategy to support U.S. operations in the \#grayzone requires having a smaller ground footprint. MQ-9 with airborne sensor and weapons capabilities allows for overwatch from a distance@usairforce 
http://bit.ly/3a8qvvO. Twitter 20 March 2020. https://twitter.com/GenAtomics_ASI/status/12411 18091192471552.

Andersen C (2014) Games of Drones: The Uneasy Future of the Soldier-Hero in Call of Duty: Black Ops II. Surveillance \& Society 12(3), 360-376.

Baudrillard J (1994) Simulacra and Simulation. University of Michigan Press, Ann Arbor MI.

Benjamin G (2016) The Cyborg Subject: Reality, Consciousness, Parallax. Palgrave, London.

Birhane A, Cummins F (2019) Algorithmic Injustices: Towards a Relational Ethics. Black in AI (NeurIPS), Vancouver, 9 December 2019, 1-4.

Burkell J. (2006) Anonymity in behavioural research: Not being unnamed, but being unknown. U. Ottawa L. \& Tech. J., 3, 189.

Campaign to Stop Killer Robots (2018) Campaign to Stop Killer Robots https://www.stopkillerrobots.org/.

Chamayou G (2015) A Theory of the Drone. The New Press, New York NY, London.

Chappelle W, McDonald K, Prince L, Goodman T, RaySannerud B, Thompson W (2014) Symptoms of Psychological Distress and Post-Traumatic Stress Disorder in United States Air Force "Drone" Operators. Military Medicine 179(8), 63-70.

Coley R, Lockwood D (2015) As above, so below: triangulating drone culture. Culture Machine 16, 119.

Crogan P (2016) War, mathematics, and simulation: Drones and (losing) control of battlespace. In Harrigan P, Kirschenbaum M (eds). Zones of Control: Perspectives on Wargaming. The MIT Press, Cambridge MA. 641-667.

Crogan P (2017) Videogames, war and operational aesthetics. In: Bourke, J., (ed). War and Art: A Visual History of Modern Conflict. Reaktion Books, London.

Cunneen M, Mullins M, Murphy F, Shannon D, Furxhi I, Ryan C (2020). Autonomous vehicles and avoiding the trolley (dilemma): vehicle perception, classification, and the challenges of framing decision ethics. Cybernetics and Systems 51(1), 5980.

Deleuze G, Guattari F (2004a) Anti-Oedipus: Capitalism and Schizophrenia. Continuum, London.

Deleuze G, Guattari, F (2004b) A Thousand Plateaus: Capitalism and Schizophrenia. Continuum, London.
Ficuciello F, Tamburrini G, Arezzo A, Villani L, Siciliano B (2019) Autonomy in surgical robots and its meaningful human control. Paladyn, Journal of Behavioral Robotics 10(1), 30-43.

Future of Life Institute (2015) Autonomous Weapons: An Open Letter from AI \& Robotics Researchers. https://futureoflife.org/open-letter-autonomousweapons/.

General Atomics (2020) About. General Atomics http://www.ga.com/about.

Harris R, Evans R (2020) MoD put pressure on regulators to delay drone safety warnings, documents reveal. The Guardian. https://www.theguardian.com/world/2020/mar/09/ mod-regulators-drone-safety-warnings.

Jablonowski M (2015) Drone It Yourself! On the decentring of 'drone stories'. Culture Machine 16, $1-15$.

Lacan J (1977) The Four Fundamental Concepts of PsychoAnalysis. The Hogarth Press, London.

Lenoir T (2000) Lenoir, T. (2000). All but war is simulation: the military-entertainment complex. Configurations 8(3), 289-335.

Lichty P (2013) Drone: Camera, Weapon,Toy: The Aestheticization of Dark Technology. Furtherfield 30 March 2013 http://www.furtherfield.org/dronecamera-weapontoy-the-aestheticization-of-darktechnology-2/.

Marx G (1999) What's in a Name? Some Reflections on the Sociology of Anonymity. The Information Society, 15(2), 99-112.

Mbembe A (2003) Necropolitics. Public Culture 15(1), 1140.

Noys B (2015) Drone Metaphysics. Culture Machine 16, 122.

Packer J, Reeves J (2017) Taking People Out: Drones, Media/Weapons, and the Coming Humanectomy. In Parks L, Kaplan C (eds) Life in the Age of Drones. Duke University Press, Durham NC. 261-281.

Piotrowska A (2017) '5,000 feet is best': Drone Warfare, Targets and Paul Virilio's 'Accident'. In Hellmich C, Purse L (eds) Disappearing War: Interdisciplinary Perspectives on Cinema and Erasure in the Post 9/11 World. Edinburgh University Press, Edinburgh. 34-55.

Pfitzmann A, Köhntopp M (2001) Anonymity, Unobservability, and Pseudonymity - A Proposal for Terminology. In: Federrath H (ed) Designing Privacy Enhancing Technologies. Lecture Notes in 
Computer Science, vol 2009. Springer, Berlin, Heidelberg, 1-9.

Sameshima P (2007) Seeing Red: A Pedagogy of Parallax : an Epistolary Bildungsroman on Artful Scholarly Inquiry. Cambria, Youngstown NY.

Sharkey A (2019) Autonomous weapons systems, killer robots and human dignity. Ethics and Information Technology 21(2), 75-87.

Singer P (2009) Wired for War: The Robotics Revolution and Conflict in the 21st Century. New York, NY: Penguin.

Singler B (2020) "Blessed by the algorithm": Theistic conceptions of artificial intelligence in online discourse. AI \& Society, 1-11.

Shaw I, Akhter M (2012) The Unbearable Humanness of Drone Warfare in FATA, Pakistan. Antipode 44(4), 1490-1509.

Stahl R (2013) What the drone saw: the cultural optics of the unmanned war. Australian Journal of International Affairs 67(5), 659-674.

Stark L (2019) Facial recognition is the plutonium of AI. XRDS: Crossroads, The ACM Magazine for Students 25(3), 50-55.

Suchman L (1994) Do Categories Have Politics? Computer Supported Cooperative Work 2, 177-190.

Thacker E (2014) Dark Media. In Galloway A, Thacker E, Wark M (eds) Excommunication: Three Inquiries in Media and Mediation. University of Chicago Press, Chicago IL. 77-150.

The Editorial Collective (1973) Toys Against the People, Science for the People 5(1), January 1973, 8-10; 3741.

Timms B. 2008. The Parallax of Landscape: Situating Celaque National Park, Honduras. In Knudsen D, Metro-Roland M, Soper A, Greer C (eds) Landscape, Tourism and Meaning. 95-108. Ashgate, Aldershot.

Yehya N (2015) The Drone: God's Eye, Death Machine, Cultural Puzzle. Culture Machine 16, 1-3.

Žižek S (2006). Interrogating the Real. Bloomsbury, London.

Žižek S (2007) The Parallax View. MIT Press, Cambridge, MA.

Žižek S (2012) Organs Without Bodies: on Deleuze and consequences. Routledge, London. 